\title{
PPAR 2 Pro12Ala Polymorphism in Relation to Free Fatty Acids Concentration and Composition in Lean Healthy Czech Individuals with and without Family History of Diabetes Type 2
}

\author{
B. BENDLOVÁ, D. VEJRAŽKOVÁ, J. VČELÁK, P. LUKÁŠOVÁ, D. BURKOŇOVÁ, \\ M. KUNEŠOVÁ, J. VRBÍKOVÁ, K. DVOŘÁKOVÁ, K. VONDRA, M. VAŇKOVÁ \\ Institute of Endocrinology, Prague, Czech Republic
}

Received November 12, 2007

Accepted January 17, 2008

On-line February 13, 2008

\section{Summary}

Free fatty acids (FFAs) are natural ligands of the PPARY2 receptor. FFA plasma concentration and composition may represent one of the factors accounting for high heterogeneity of conclusions concerning the effect of the Pro12Ala on BMI, insulin sensitivity or diabetes type 2 (DM2) susceptibility. Our objective was to investigate the relation and possible interactions between the Pro12Ala polymorphism and FFA status, metabolic markers, and body composition in 324 lean nondiabetic subjects (M/F: 99/225; age $32 \pm 11$ years; BMI $23.9 \pm 4.0 \mathrm{~kg} / \mathrm{m}^{2}$ ) with and without family history of DM2. Family history of DM2 was associated with lower \% PUFA and slightly higher \% MUFA. The presence of Pro12Ala polymorphism was not associated with fasting plasma FFA concentration or composition, anthropometric or metabolic markers of glucose and lipid metabolism in tested population. However, the interaction of carriership status with FFA levels influenced the basal glucose levels, insulin sensitivity and disposition indices, triglycerides, HDL-cholesterol and leptin levels, especially in women. The metabolic effects of 12Ala carriership were influenced by FFA levels - the beneficial role of 12Ala was seen only in the presence of low concentration of plasma FFA. Surprisingly, a high PUFA/SFA ratio was associated with lower insulin sensitivity, the protective effect of 12Ala allele was apparent in subjects with family history of DM2. On the basis of our findings and published data we recommend the genotyping of diabetic patients for Pro12Ala polymorphism of the PPAR $\gamma 2$ gene before treatment with thiazolidinediones and education of subjects regarding diet and physical activity, which modulate metabolic outcomes.

\section{Key words}

PPARy2 Pro12Ala polymorphism • Free fatty acids concentration • Free fatty acids - Composition - Polyunsaturated fatty acids • Insulin sensitivity • Offspring • Diabetes type 2

\section{Corresponding author}

B. Bendlová, Institute of Endocrinology, Národní třída 8, 11694 Prague 1, Czech Republic. E-mail: bbendlova@endo.cz

\section{Introduction}

The prevalence of obesity and diabetes mellitus type 2 (DM2) has been increasing dramatically throughout the entire world in the last decades. There is growing evidence that the interaction between genetic factors and environmental factors such as dietary habits, physical activity, stress, chemical toxins etc. plays a crucial role in the pathogenesis of these multifactorial diseases (Barroso 2005, Uusitupa 2005, Cocozza 2007). In spite of intensive study, the pathogenetic mechanisms for this are still not completely understood. It is suggested that the major metabolic defect is the impaired fat metabolism, which is associated with the development of insulin resistance, the key feature of metabolic syndrome (McGarry 2002, Cahová et al. 2007).

Free fatty acids are one of the major dietetic factors, which influence insulin sensitivity and beta-cell function (Keller 2006). Numerous studies over the past 25 years have demonstrated that saturated (SFA), monounsaturated (MUFA), and polyunsaturated fatty acids (PUFA) do not regulate glucose and lipid metabolism in the same way or with the same outcomes (Storlien et al. 1991, McGarry 2002). Dietary polyunsaturated fatty acids (PUFAs), particularly the long-chain n-3 fatty acids of fish oils, improve the anomalies in glucose and lipid metabolism associated with fat ingestion. PUFAs rich in long chain n-3 fatty acids markedly reduce hepatic TG

PHYSIOLOGICAL RESEARCH • ISSN 0862-8408 (print) • ISSN 1802-9973 (online)

(c) 2008 Institute of Physiology v.v.i., Academy of Sciences of the Czech Republic, Prague, Czech Republic

Fax +420 241062 164, e-mail: physres@biomed.cas.cz,www.biomed.cas.cz/physiolres 
output by suppressing hepatic de novo fatty acid and TG biosynthesis, and increasing hepatic fatty acid oxidation (Takada et al. 1994, Žák et al. 2005, Kunešová et al. 2006) by modulating the expression of hepatic glycolytic and lipogenic enzymes including pyruvate kinase, fatty acid synthase, and glucokinase (Jump et al. 1994). In contrast to the consistent beneficial effects of polyunsaturated fats, deleterious effects of saturated fats were found. There is evidence from epidemiological studies that appears to link higher saturated fat intake with insulin resistance, even after adjustment for adiposity (Parker et al. 1993). Furthermore, the effects of dietary fats were more pronounced in sedentary individuals, whereas increased levels of physical activity attenuated the relationship between dietary fat intake and fasting insulin. This indicates that an interaction between fatty acid composition and level of physical activity may play a role (Feskens et al. 1994). Monounsaturated fatty acids (MUFAs) intake has been shown to be beneficial in short-term trials in DM2 patients (Campbell et al. 1994). With a high-MUFA diet, blood glucose control improves, postprandial insulin levels decrease, insulin sensitivity improves, TG levels decrease, and high-density lipoprotein (HDL) cholesterol concentrations either remain unchanged or increase (Parillo et al. 1992). However, not all epidemiological studies show MUFAs to have a beneficial effect on the indices of insulin resistance and diabetes outcome (Marshall et al. 1994).

The Pro12Ala polymorphism of the PPAR 2 gene, free fatty acids and insulin sensitivity

The gene encoding for peroxisome proliferatoractivated receptor- $\gamma(P P A R G)$ plays a key role among the genetic factors that significantly influence insulin sensitivity (Kersten et al. 2000, Lazar 2005). The PPAR $\gamma 2$ is a member of the nuclear hormone receptor family. It is a transcription factor that has been identified as a functional receptor for the thiazolidinedione (TZD) class of insulinsensitizing drugs (Lehmann et al. 1995). It is expressed at high level in adipose tissue (Vidal-Puig et al. 1997, Fajas et al. 1997), where it modulates the expression of target genes implicated in adipocyte differenciation and glucose homeostasis. Expression of the PPAR $\gamma$ has also been demonstrated in human beta-cells (Dubois et al. 2000). Therefore, the PPAR $\gamma 2$ represents a candidate gene for type 2 diabetes mellitus (DM2). The importance of the gene in the control of human insulin sensitivity has been confirmed by the finding of severe insulin-resistant diabetes in families with loss of function mutations in the gene (Barroso et al. 1999). Moreover, gain of function mutation has been associated with severe obesity in men (Bluher and Paschke 2003). The Pro12Ala single nucleotide polymorphism in exon B of the gene (Yen et al. 1997) was found to lower transactivation capacity (Deeb et al. 1998). Numerous studies have examined the relationship between this polymorphism and metabolic parameters with variable results reviewed by (Stumvoll and Haring 2002a). In terms of adiposity, increased, decreased, as well as neutral effects of the 12Ala allele were reported. Similarly, conflicting results were reported in terms of DM2 susceptibility. However, the metaanalysis of published association studies confirmed a modest (1.25fold) but significant $(\mathrm{p}=0.002)$ increase in DM2 risk with the 12Pro allele, i.e. protective effect of the 12Ala variant (Altshuler et al. 2000).

Free fatty acids (FFAs) are natural ligands of the PPAR 2 receptor (Forman et al. 1995, Lazar 2005). It is not completely clear what effect FFA composition has on the gene's activity and how this effect is modulated by the presence of the Pro12Ala polymorphism. Several factors may account for high heterogeneity of conclusions reporting the effect of the Pro12Ala polymorphism on BMI, insulin sensitivity or DM2 susceptibility and FFAs plasma composition may represent one of them. Recently, several studies have been conducted to study gene-nutrient interactions of Pro12Ala polymorphism in basal as well as in diet induced conditions (Luan et al. 2001, Lindi et al. 2001, Stefan et al. 2001, Vaccaro et al. 2002, Lindi et al. 2003, Memisoglu et al. 2003, Robittaile et al. 2003, Franks et al. 2004, Pisabarro et al. 2004, Tan et al. 2006, Soriguer et al. 2006, Vaccaro et al. 2007). However, the results are not fully concordant.

The objective of our study was to investigate the relation of the PPAR $\gamma 2$ Pro12Ala polymorphism, basal and oGTT stimulated plasma concentration, and composition of FFAs and markers of glucose and lipid metabolism as well as body composition in lean healthy subjects with and without family history of diabetes type 2 and to study the possible modulating effects of the FFAs status on the metabolic outcomes.

\section{Methods}

\section{Study subjects}

We studied 324 lean nondiabetic subjects (M/F: 99/225; age $32 \pm 11$ years; BMI $23.9 \pm 4.0 \mathrm{~kg} / \mathrm{m}^{2}$ ) in terms of biochemical parameters related to glucose and lipid metabolism, body composition and Pro12Ala genotyping. 
A subgroup of the participants had family history $(\mathrm{FH})$ of DM2 ( $\mathrm{n}=106, \mathrm{M} / \mathrm{F}$ 33/73) (FH+, i.e. DM2 diagnosed by the criteria of the World Health Organization was present in one or both parents). The study protocol was in accordance with institutional ethic guidelines and national rules and all the subjects gave their written informed consent to participate in the study.

\section{Clinical and biochemical characterization}

Anthropometric data was obtained in the fasting state. Body weight, height, waist and hip circumferences were measured in all participants in order to calculate body mass index (BMI) and to evaluate body fat distribution by means of waist circumference and waist to hip ratio (WHR). Furthermore, 14 skinfolds were measured and body composition ( $\%$ of subcutaneous fat mass, $\%$ of muscle mass, and \% of bone mass) was then calculated using the ANTROPO program (Bláha 1991).

After an overnight fast, venous blood samples were taken. Glucose metabolism was characterized by blood glucose $\left(\mathrm{G}_{0}\right.$; glucose oxidase method, Beckman Glucose Analyser 2), immunoreactive insulin ( $\mathrm{I}_{0}$; immunoradiometric assay kit, Immunotech IRMA, Czech Rep), C-peptide ( $\mathrm{Cp}_{0}$; immunoradiometric assay kit, Immunotech IRMA, Czech Rep), and also proinsulin (ELISA kit, DRG Diagnostics, Germany). The 3-hour oral glucose tolerance test (oGTT) with $75 \mathrm{~g}$ of glucose load and intravenous insulin tolerance test (ivITT) according to Young et al. (1996) were performed in all subjects. Areas under the oGTT glycemic, C-peptide and insulin curves were calculated (AUC). Lipid profile was assessed by total cholesterol (CH), HDL cholesterol (HDL-CH), lowdensity lipoprotein cholesterol (LDL-CH) and triglycerides (TG) concentrations (automatic biochemical analyser Integra 400+, Roche Diagnostics GmbH, Germany). To assess insulin sensitivity and beta-cell function, the homeostasis models 1/HOMA R and HOMA F assessment (Matthews et al. 1985), Matsuda index (Matsuda and De Fronzo 1999) and insulinogenic index were used (1/HOMAR $=1 /\left(\mathrm{I}_{0} * \mathrm{G}_{0} / 22.5\right), \quad$ HOMA $\mathrm{F}=20 * \mathrm{I}_{0} /\left(\mathrm{G}_{0}-3.5\right)$, Matsuda index $=10 \% \sqrt{ }\left(\right.$ meanI $\left._{0} * m_{e a n G_{0}} * \mathrm{G}_{0} * \mathrm{I}_{0}\right)$, insulinogenic index $\left.=\left(\mathrm{I}_{0}-\mathrm{I}_{0}\right) /\left(\mathrm{G}_{30}-\mathrm{G}_{0}\right)\right)$. Moreover, the product of insulin sensitivity and beta cell function, i.e. disposition indices (DI), were calculated as follows: $\mathrm{DI}_{1}=1 /$ HOMA $\mathrm{R}^{*}\left(\mathrm{I}_{30}-\mathrm{I}_{0}\right) /\left(\mathrm{G}_{30}-\mathrm{G}_{0}\right), \mathrm{DI}_{2}=$ Matsuda index *HOMA F. The basal FFA $\left(\mathrm{FFA}_{0}\right)$ and oGTT-stimulated concentrations in the 60th $\left(\mathrm{FFA}_{60}\right)$ and 180th min $\left(\mathrm{FFA}_{180}\right)$ of oGTT were evaluated by spectrophotometric method using NEFA C ACS-ACOD (Wako Chemicals GmbH,
Germany) and FFA composition was assessed by gas chromatography (GC-14A instrument, Shimadzu, Kyoto, Japan) after extraction and subsequent derivatization by isooctane-methylchloroformiate, 5:1. Heptadecanoic acid (C17:0) was used as internal standard (Hušek et al. 2002). Saturated fatty acids (SFA) fraction included C12:0, C14:0, C16:0, C18:0. Monounsaturated fatty acids (MUFA) fraction consisted of C16:1n-7, C18:1n-7, C18:1n-9, C20:1n-9 and polyunsaturated fatty acids (PUFA) fraction of C18:2n-6, C18:3n-3, C20:3n-6, C20:4n-6, C22:6n-3. The total concentrations of fatty acids type groups ( $\Sigma$ SFA, $\Sigma$ MUFA, $\Sigma$ PUFA) as well as their percentage shares ( $\%$ SFA, \% MUFA, \% PUFA) out of total FFAs derived from GC method were evaluated.

\section{PPAR 2 Pro12Ala genotyping}

DNA extracted from peripheral leucocytes was used to genotype for the Pro12Ala polymorphism by the SSCP method as previously described in literature (Niskanen et al. 2003). Positive and negative controls were used in every run.

\section{Statistical analysis}

For the statistical evaluation, NCSS 2004 (Statistical Solutions, Saugus, Ma, USA) software was used. Data is given as means and SEMs or percentages. The Chi-square test was used to assess deviation from Hardy-Weinberg equilibrium of genotypic frequencies by calculating expected frequencies of genotypes. Frequencies were compared by Fisher's exact tests. Differences in biochemical and anthropometric data between the compared groups were tested by non-parametric MannWhitney test or by ANOVA (after the data transformation to normal distribution). When appropriate, data was adjusted for age or for age and BMI using the GLM ANOVA. For quartile comparisons the cut off values of 25 th and 75 th percentiles of FFA0 concentration, \% SFA, $\Sigma$ SFA, \% MUFA, $\Sigma$ MUFA, \% PUFA, $\Sigma$ PUFA, and PUFA/SFA ratio were stated for subjects with and without FH of DM2 separately. The P values $<0.05$ (two tailed) were considered to be significant.

\section{Results}

\section{Comparison of subjects with and without FH of DM2}

General clinical characteristics of the study population are given in Table 1 . The subjects with and without FH of DM2 differed significantly in age. Even after the adjustment for age all measured anthropometric 
Table 1. Phenotypical characterization of study subjects with (FH+) and without family history (FH-) of DM2.

\begin{tabular}{|c|c|c|c|}
\hline & $\begin{array}{l}\text { FH+ } \\
\text { (males/females) }\end{array}$ & $\begin{array}{l}\text { FH- } \\
\text { (males/females) }\end{array}$ & $\begin{array}{l}\text { P } \\
\text { ANOVA }\end{array}$ \\
\hline$n$ & $33 / 73$ & $66 / 152$ & - \\
\hline Age (years) & $39.4 \pm 1.5 / 36.9 \pm 1.5$ & $29.4 \pm 1 / 29.5 \pm 0.9$ & $0.000 / 0.000^{\mathrm{a}}$ \\
\hline$B M I\left(\mathrm{~kg} / \mathrm{m}^{2}\right)$ & $25.8 \pm 0.6 / 24.3 \pm 0.4$ & $24.2 \pm 0.4 / 23.1 \pm 0.3$ & $0.05 / \mathbf{0 . 0 3}$ \\
\hline WHR & $0.88 \pm 0.01 / 0.75 \pm 0.01$ & $0.84 \pm 0.01 / 0.73 \pm 0.004$ & $0.001 / 0.02$ \\
\hline Waist $(\mathrm{cm})$ & $89.5 \pm 1.6 / 75.7 \pm 1$ & $83.7 \pm 1.1 / 72.8 \pm 0.7$ & $0.01 / 0.02$ \\
\hline Subcutaneous fat (\%) & $17.9 \pm 1.1 / 26 \pm 0.8$ & $16.3 \pm 0.8 / 24.5 \pm 0.6$ & $0.3 / 0.14$ \\
\hline Muscle/fat ratio & $3.1 \pm 0.3 / 1.7 \pm 0.1$ & $3.4 \pm 0.2 / 1.8 \pm 0.1$ & $0.4 / 0.23$ \\
\hline$T G(\mathrm{mmol} / \mathrm{l})$ & $1.1 \pm 0.06$ & $1 \pm 0.04$ & 0.09 \\
\hline $\mathrm{CH}(\mathrm{mmol} / \mathrm{l})$ & $4.7 \pm 0.1$ & $4.6 \pm 0.1$ & 0.2 \\
\hline$H D L-C H(\mathrm{mmol} / \mathrm{l})$ & $1.1 \pm 0.05 / 1.5 \pm 0.04$ & $1.2 \pm 0.04 / 1.6 \pm 0.03$ & $0.23 / 0.2$ \\
\hline LDL-CH $(\mathrm{mmol} / \mathrm{l})$ & $2.8 \pm 0.1$ & $2.6 \pm 0.1$ & 0.1 \\
\hline Leptin $(n g / m l)$ & $3.7 \pm 0.6 / 12 \pm 1.4$ & $5 \pm 0.4 / 13 \pm 1.1$ & $0.1 / 0.6$ \\
\hline$F F A_{0}(\mathrm{mmol} / \mathrm{l})$ & $0.6 \pm 0.03$ & $0.5 \pm 0.02$ & 0.2 \\
\hline$\Sigma S F A(\mu \mathrm{mol} / \mathrm{l})$ & $178 \pm 8$ & $183 \pm 6$ & 0.8 \\
\hline$\% S F A$ & $38 \pm 0.6$ & $38 \pm 0.5$ & 0.9 \\
\hline$\Sigma M U F A(\mu \mathrm{mol} / \mathrm{l})$ & $197 \pm 10$ & $191 \pm 7$ & 0.6 \\
\hline$\% M U F A$ & $41 \pm 0.7$ & $40 \pm 0.5$ & $0.06^{\mathrm{d}}$ \\
\hline$\Sigma P U F A(\mu \mathrm{mol} / \mathrm{l})$ & $97 \pm 5$ & $107 \pm 4$ & 0.2 \\
\hline$\% P U F A$ & $21 \pm 0.5$ & $22 \pm 0.4$ & $0.02^{b}$ \\
\hline PUFA/SFA ratio & $0.56 \pm 0.02$ & $0.6 \pm 0.02$ & 0.09 \\
\hline$G_{0}(\mathrm{mmol} / \mathrm{l})$ & $4.7 \pm 0.05$ & $4.6 \pm 0.03$ & 0.1 \\
\hline$C p_{0}($ nmol/l) & $0.7 \pm 0.03$ & $0.6 \pm 0.02$ & $0.048^{c}$ \\
\hline$I_{0}(m I U / l)$ & $8 \pm 0.4$ & $6.7 \pm 0.3$ & 0.02 \\
\hline$A U C G 7(3 h$ OGTT) & $1022 \pm 18$ & $973 \pm 12$ & $\mathbf{0 . 0 3 8 ^ { \mathrm { c } }}$ \\
\hline$A U C C p 7(3 h O G T T)$ & $412 \pm 13$ & $387 \pm 9$ & 0.14 \\
\hline$A U C I 7(3 h$ OGTT) & $6350 \pm 513$ & $5466 \pm 367$ & 0.19 \\
\hline AUC ivITT (15min) & $37.9 \pm 0.6$ & $38.1 \pm 0.4$ & 0.79 \\
\hline HOMA R (mIU.mmol. $\left.l^{-2}\right)$ & $1.7 \pm 0.1$ & $1.4 \pm 0.07$ & $0.012^{c}$ \\
\hline HOMA F (mIU/mmol) & $131 \pm 10$ & $136 \pm 7$ & 0.7 \\
\hline Matsuda index $\left(m m o l^{-1} \cdot m I U^{-1} \cdot l^{2}\right)$ & $169 \pm 10$ & $162 \pm 7$ & 0.56 \\
\hline Insulinogenic index (mIU/mmol) & $15.2 \pm 1.9$ & $18.5 \pm 1.4$ & 0.19 \\
\hline $1 / H O M A R *$ Insulinogenic index & $13.5 \pm 2.5$ & $17.3 \pm 1.8$ & 0.25 \\
\hline Matsuda index $* H O M A F$ & $17183 \pm 1026$ & $18481 \pm 730$ & 0.33 \\
\hline
\end{tabular}

Data adjusted for age are shown as MEAN \pm SEM; ${ }^{a}$ Mann-Whitney test; ${ }^{b}$ after adjustment for age and $B M I ~ p=0.02 ;{ }^{c}$ after adjustment for age and BMI $p=N S$, ${ }^{d}$ adjustment for age and BMI $p=0.037$

parameters except for $\%$ of subcutaneous fat were significantly higher in subjects with FH of DM2. There were no differences in lipid spectra (TG, total $\mathrm{CH}$, HDL$\mathrm{CH}$, LDL-CH) nor in basal or oGTT stimulated FFA levels between the two groups. In terms of FFA composition, subjects with FH of DM2 displayed significantly lower \% PUFA, tendency toward lower PUFA/SFA ratios and slightly higher \% MUFA. After adjustment for age and BMI almost all significances disappeared except of $\%$ PUFA $(p=0.012)$ and $\%$ MUFA $(p=0.037)$. As to glucose tolerance, basal insulin, basal Cpeptide levels, areas under the glycemic (AUC G7) and insulinemic oGTT curves (AUC I7) and index of insulin resistance HOMA $\mathrm{R}$ were significantly higher in DM2 offspring after adjustment for age but not after adjustment for age and BMI. 
Table 2. Genotype and allelic frequencies of PPAR $\gamma 2$ Pro12Ala polymorphism in study subjects with (FH+) and without (FH-) family history of DM2.

\begin{tabular}{lccc}
\hline & FH+ & FH- & Fisher's exact test \\
\hline Pro/Pro & $75(70.8 \%)$ & $158(72.5 \%)$ & \\
Pro/Ala & $27(25.4 \%)$ & $56(25.7 \%)$ & $\mathrm{Chi}^{2}=0.018 ; \mathrm{p}=0.62$ \\
Ala/Ala & $4(3.8 \%)$ & $4(1.8 \%)$ & \\
Pro & $177(83.5 \%)$ & $372(85.3 \%)$ & $\mathrm{Chi}^{2}=0.076 ; \mathrm{p}=0.56$ \\
Ala & $35(16.5 \%)$ & $64(14.7 \%)$ & \\
\hline
\end{tabular}

PPAR 2 Pro12Ala genotype distribution and the genotype-phenotype associations with respect to $\mathrm{FH}$ of $D M 2$

PPAR $\gamma 2$ Pro12Ala genotype and allelic distribution in the studied cohorts is given in Table 2. The genotype distribution was in Hardy-Weinberg equilibrium. The frequency of the 12Ala allele was $15.3 \%$, i.e. similar as reported in other studies in Caucasians. Only 8 subjects were homozygous for the 12Ala variant. As no difference in circulating FFA was observed between 12Ala homozygotes and heterozygotes, these subjects were pooled together in the analysis and are referred to as 12Ala carriers. There were no differences in the genotype and allelic frequencies between DM2 offspring and controls.

The frequency of the 12Ala carriers was also analyzed and compared across increasing quartiles of basal FFA concentrations as well as across quartiles of $\%$ SFA, \% MUFA, $\%$ PUFA, $\Sigma$ SFA, $\Sigma$ MUFA, $\Sigma$ PUFA, and PUFA/SFA ratio. However, no relation was observed concerning the 12Ala carriers distribution across the quartile groups (data not shown).

Carriers and non-carriers of the 12Ala variant showed very similar basal FFA concentrations and also other biochemical and anthropometric data (concerning anthropometry, HDL-cholesterol and leptin, males and females were analyzed separately) were comparable across the genotypes in subjects with and without $\mathrm{FH}$ of DM2 (Table 3). Concerning the FFA composition, significant difference between 12Pro homozygotes and 12Ala carriers in basal MUFA concentration, but not in $\%$ MUFA, was found. This parameter was higher in 12Ala carriers without FH of DM2 (adjusted for age, $\mathrm{p}=0.03$ ). The carriers of the 12Ala variant had higher leptin levels, significance was observed especially in women with FH of DM2. However, the 12Ala carriers did not differ from their 12Pro counterparts in parameters characterizing glucose tolerance, insulin resistance and beta-cell function.
The interaction of Pro12Ala genotype with FFA concentration and composition and its influence on insulin sensitivity a beta-cell function - comparison of opposite quartiles

To investigate the putative interaction of the polymorphism with FFA concentration and composition, and its possible influence on anthropometric and biochemical data, especially on insulin sensitivity and insulin secretion, the subjects carrying the same genotype whose basal FFA concentrations, \% PUFA, \% MUFA, $\%$ SFA, PUFA, MUFA, SFA total concentrations and PUFA/SFA ratio were the lowest $(<25$ th percentile) and the highest ( $>75$ th percentile) were compared. Similarly, biochemical and anthropometric data were also compared between 12Ala carriers and 12Pro homozygotes within the same quartile of the above mentioned parameters. At first we tested these interactions in subjects with and without FH of DM2 separately. The values of whole body insulin sensitivity (Matsuda index) in the opposite quartiles of FFA concentration and composition, respectively, with respect to genotype and $\mathrm{FH}$ of DM2 are given in Fig. 1. The interaction of genotype with plasma PUFA/SFA ratio significantly influenced insulin sensitivity. A high PUFA/SFA ratio was associated with lower insulin sensitivity, the protective effect of 12Ala allele was apparent in subjects with family history of DM2. When the subjects both with and without FH of DM2 in the appropriate quartiles were pooled together to increase the statistical power, the AUC G7, AUC Cp7 were significantly higher in the upper quartile of basal FFA in both genotypes (GLM Anova, all $\mathrm{p}<0.001$ ) (Table 4). Deterioration of insulin sensitivity as well as insulin secretion in the upper quartile of basal FFA concentration regardless of carriership was apparent. Moreover, in 12Ala carriers significantly lower disposition indices and leptin levels in females in the upper quartile in comparison with the lowest one were found. It was obvious that the genotype 12Ala is associated with the best values of insulin sensitivity 


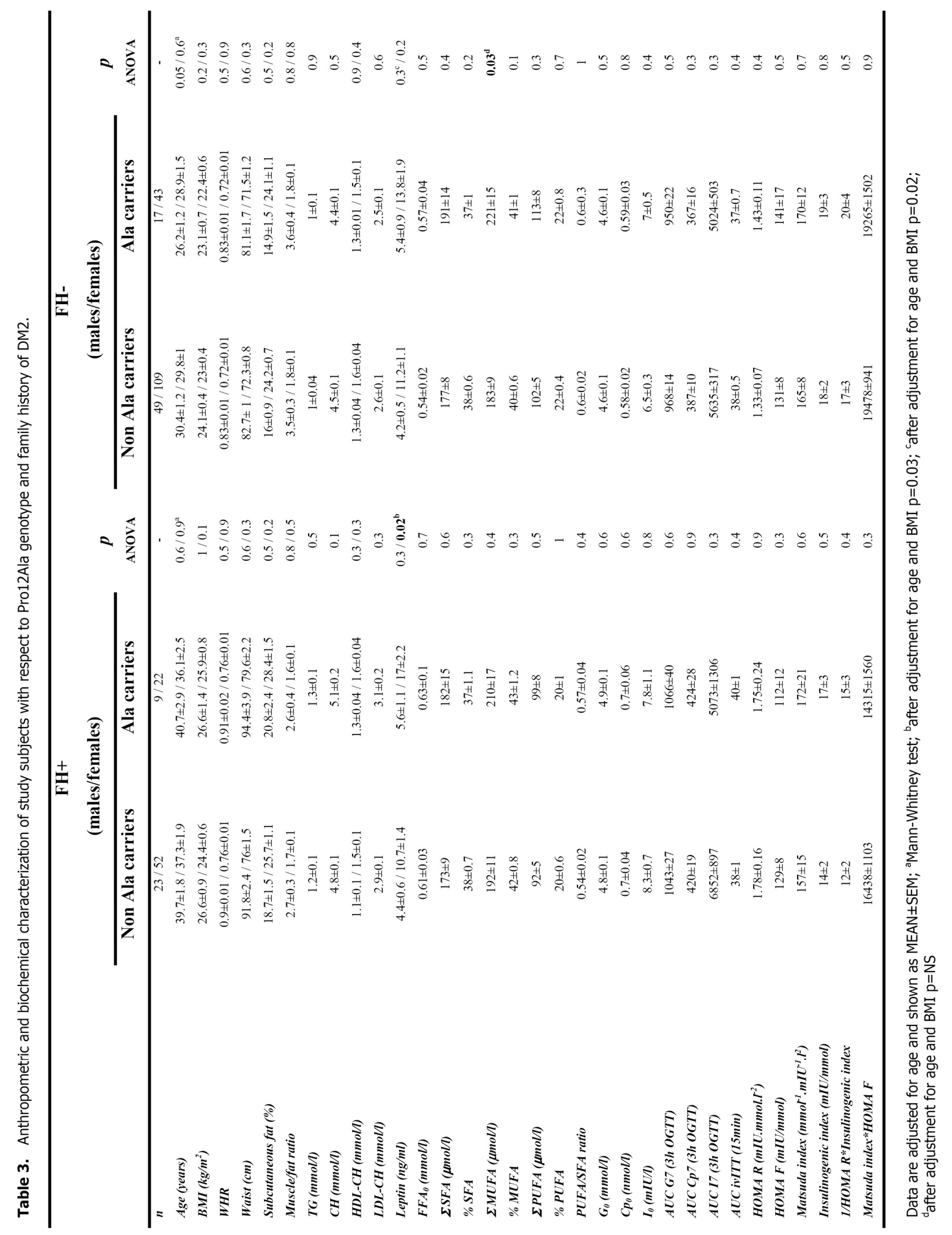



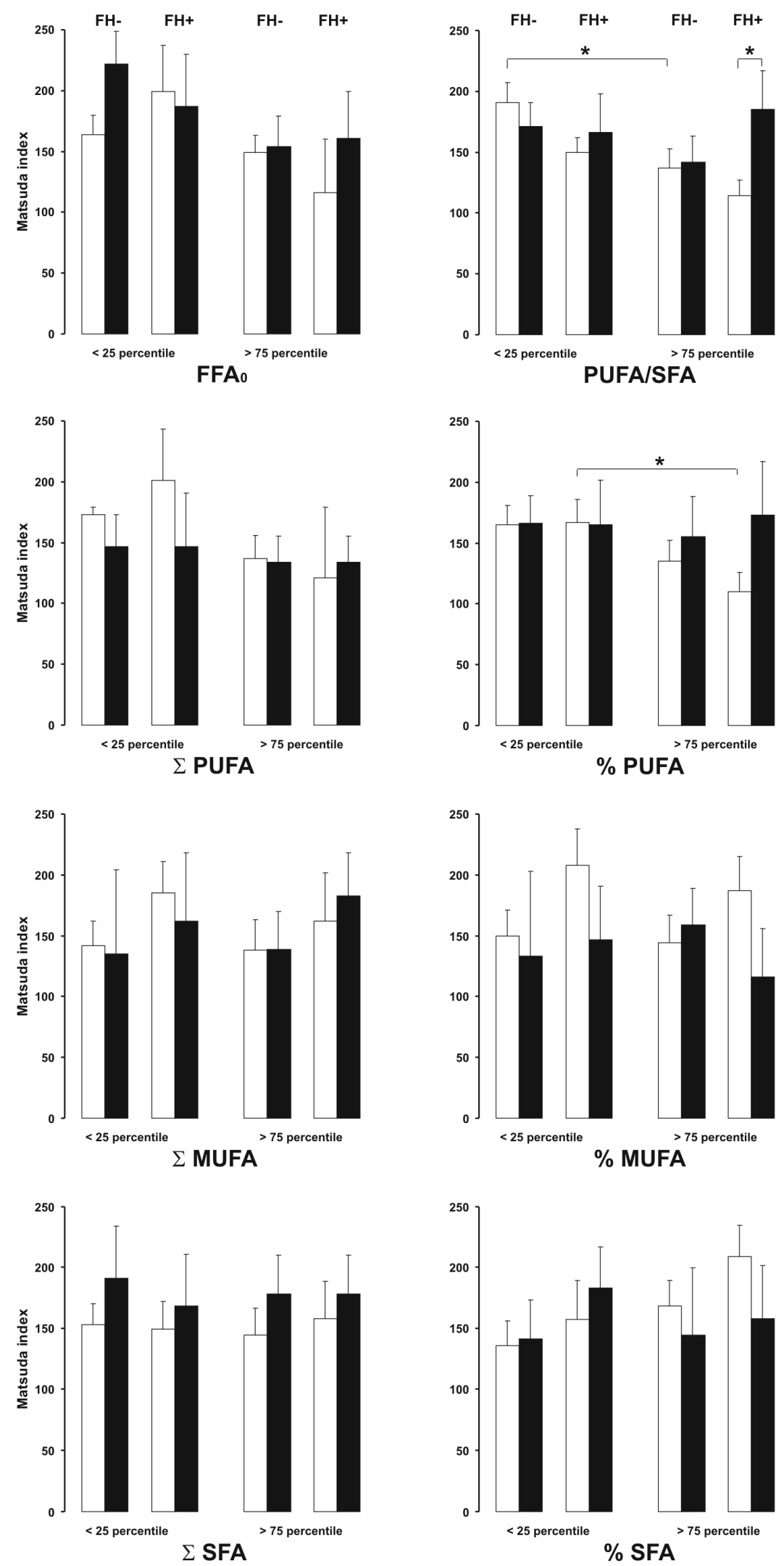

Fig. 1. Whole body insulin sensitivity (Matsuda index) in the opposite quartiles of free fatty acids concentration and composition with respect of genotype and FH of DM2. Blank bars: 12Pro homozygotes, black bars: 12Ala carriers 
Table 4. Comparison of lipid spectra, leptin levels and parameters of glucose metabolism in 12Ala carriers and non-carriers (irrespectively of family history of DM2) in relation to basal free fatty acids levels.

\begin{tabular}{|c|c|c|c|c|c|}
\hline & \multicolumn{4}{|c|}{ FFAs $_{0}$ quartiles } & \multirow{3}{*}{$\begin{array}{c}\mathbf{p} \\
\text { ANOVA }\end{array}$} \\
\hline & $<25$ th & $>75$ th & $<25$ th & $>75$ th & \\
\hline & \multicolumn{2}{|c|}{ Non Ala carriers } & \multicolumn{2}{|c|}{ Ala carriers } & \\
\hline$n$ & 49 & 50 & 24 & 26 & \\
\hline$T G$ & $1.03 \pm 0.1$ & $1.08 \pm 0.1$ & $0.89 \pm 0.1$ & $1.37 \pm 0.1$ & 0.045 \\
\hline $\mathrm{CH}$ & $4.5 \pm 0.1$ & $4.7 \pm 0.1$ & $4.8 \pm 0.2$ & $4.5 \pm 0.2$ & 0.29 \\
\hline$L D L-C H$ & $2.7 \pm 0.1$ & $2.7 \pm 0.1$ & $2.6 \pm 0.2$ & $2.5 \pm 0.2$ & 0.82 \\
\hline HDL-CH women & $1.53 \pm 0.1$ & $1.68 \pm 0.1$ & $1.73 \pm 0.1$ & $1.49 \pm 0.1$ & 0.015 \\
\hline$H D L-C H$ men & $1.17 \pm 0.1$ & $1.22 \pm 0.1$ & $1.27 \pm 0.1$ & $1.17 \pm 0.1$ & 0.42 \\
\hline$S F A$ & $142 \pm 13$ & $228 \pm 12$ & $164 \pm 22$ & $242 \pm 20$ & 0.83 \\
\hline$\% S F A$ & $40 \pm 1$ & $36 \pm 1$ & $38 \pm 2$ & $36 \pm 1$ & 0.61 \\
\hline$M U F A$ & $129 \pm 14$ & $268 \pm 13$ & $173 \pm 23$ & $301 \pm 21$ & 0.76 \\
\hline$\% M U F A$ & $38 \pm 1$ & $43 \pm 1$ & $41 \pm 2$ & $44 \pm 2$ & 0.51 \\
\hline$P U F A$ & $81 \pm 8$ & $132 \pm 7$ & $87 \pm 13$ & $134 \pm 12$ & 0.88 \\
\hline$\%$ PUFA & $22 \pm 1$ & $21 \pm 1$ & $20 \pm 1$ & $19 \pm 1$ & 0.76 \\
\hline$P U F A / S F A$ & $0.57 \pm 0.03$ & $0.61 \pm 0.03$ & $0.55 \pm 0.04$ & $0.56 \pm 0.04$ & 0.72 \\
\hline Leptin women & $12.4 \pm 1.7$ & $12 \pm 1.4$ & $22.5 \pm 2.2$ & $10.7 \pm 2.3$ & 0.008 \\
\hline Leptin men & $4.8 \pm 0.5$ & $4.9 \pm 0.7$ & $5.9 \pm 1.3$ & $4.7 \pm 0.8$ & 0.51 \\
\hline$G_{0}$ & $4.8 \pm 0.1$ & $4.6 \pm 0.1$ & $4.5 \pm 0.1$ & $4.9 \pm 0.1$ & 0.004 \\
\hline$C p_{0}$ & $0.63 \pm 0.03$ & $0.58 \pm 0.03$ & $0.62 \pm 0.05$ & $0.64 \pm 0.05$ & 0.29 \\
\hline$I_{0}$ & $7.1 \pm 0.6$ & $7.4 \pm 0.6$ & $6.7 \pm 0.9$ & $7.7 \pm 0.9$ & 0.62 \\
\hline AUC G7 (3h OGTT) & $937 \pm 23$ & $1064 \pm 23$ & $902 \pm 33$ & $1073 \pm 33$ & 0.43 \\
\hline$A U C C p 7$ (3h OGTT) & $364 \pm 17$ & $434 \pm 17$ & $321 \pm 24$ & $423 \pm 24$ & 0.46 \\
\hline AUC I7 (3h OGTT) & $4850 \pm 500$ & $6348 \pm 463$ & $4080 \pm 688$ & $6188 \pm 655$ & 0.61 \\
\hline AUC ivITT (15min) & $38 \pm 1$ & $39 \pm 1$ & $36 \pm 1$ & $39 \pm 1$ & 0.12 \\
\hline HOMA R & $1.55 \pm 0.13$ & $1.46 \pm 0.13$ & $1.37 \pm 0.18$ & $1.68 \pm 0.18$ & 0.22 \\
\hline Matsuda index & $174 \pm 15$ & $144 \pm 15$ & $203 \pm 22$ & $160 \pm 20$ & 0.71 \\
\hline Insulinogenic index & $18.3 \pm 3.6$ & $16 \pm 3.5$ & $27.8 \pm 4.9$ & $13.1 \pm 4.7$ & 0.16 \\
\hline$H O M A F$ & $141 \pm 16$ & $133 \pm 16$ & $148 \pm 23$ & $123 \pm 23$ & 0.66 \\
\hline Matsuda index*HOMA $F$ & $17614 \pm 1382$ & $17235 \pm 1331$ & $21828 \pm 1955$ & $13477 \pm 1777$ & 0.018 \\
\hline $1 / H O M A R *$ insulinogenic index & $15.5 \pm 4.6$ & $12.8 \pm 4.4$ & $37.2 \pm 6.3$ & $9.3 \pm 6.1$ & 0.024 \\
\hline
\end{tabular}

Data are adjusted for age and BMI and shown as MEAN \pm SEM

parameters as well as disposition indices in the presence of low FFA concentration. But in the presence of high basal serum FFA this genotype was associated with the worse glucose tolerance comparable with 12Pro carriers in the upper quartile. Also, the highest TG and the lowest level of HDL-CH in women was measured in 12Ala carriers in presence of high levels of basal FFA (Table 4). Similar trends were seen when quartiles of $\Sigma$ SFA were evaluated (data not shown). No differences in the tested parameters between 12Ala carriers in lower vs. upper quartile of MUFA, PUFA total concentrations and \% and PUFA/SFA ratio were revealed, and no differences were found between 12Ala and 12Pro carriers in the appropriate quartiles.

\section{Discussion}

The relationship of a relatively common plymorphism Pro12Ala of PPAR $\gamma 2$ gene and circulating fasting and stimulated (by diet or by functional tests) FFAs and insulin sensitivity has been evaluated in several recent studies (Luan et al. 2001, Lindi et al. 2001, Stefan et al. 2001, Vaccaro et al. 2002, Lindi et al. 2003, Memisoglu et al 2003, Robittaile et al. 2003, Franks et al. 
2004, Pisabarro et al. 2004, Tan et al. 2006, Soriguer et al. 2006, Vaccaro et al. 2007). But the results are inconsistent. The question about the molecular mechanisms of the PPAR $\gamma 2$ modulation of insulin action, glucose homeostasis and body weight and the role of FFAs plasma levels and FFA composition is still open.

We studied these interactions in lean healthy adults with or without family history of DM2 in fasting and in oGTT stimulated conditions. We confirmed (Groop et al. 1996) the anthropometric and metabolic shift in the subjects with family history of DM2 to the "metabolic syndrome risk phenotype" although they were relatively young and lean. Interestingly, there were no differences in the lipid spectra (TG, CH, HDL-CH, LDL$\mathrm{CH})$ or basal FFAs. Positive FH of DM2 was associated with lower \% PUFAs, even after adjustment for age. We could not exclude dietary influence because we did not monitor the food intake exactly over a period before the study, but it is very improbably that there would be different habitual diet (esp. regarding the PUFAs content) in subjects with and without FH of DM2. The reduction of \% PUFA in the DM2 offspring could be caused by the reduced activities of delta 6 and delta 5 desaturases that are essential for the formation of the long-chain metabolites of FFA in the early phase of the insulin resistant state of these subjects. The impaired activities of delta6 and delta5 desaturases were found in experimentaly induced diabetic rats and in spontaneously diabetic rats where their activity was restored by insulin treatment (reviewed by Vessby et al. 2002). The activity of fatty acid desaturases is regulated by long-chain polyunsaturated fatty acids and insulin and is probably also dependent on physical activity (Vessby et al. 2002) and caloric restriction (Das 2005).

The role of PPAR 2 in fat metabolism, insulin sensitivity and regulation of body weight is very complex and is modulated by many factors. PPAR $\gamma 2$ is activated by a number of mono and polyunsaturated fatty acids in vitro (Forman et al. 1995, Schoonjans et al. 1995). Thus, FFA status may result in differential gene activation in 12Ala carriers compared with non-carriers. On the other hand plasma fatty acid composition seems to be regulated by PPAR 2 itself (Vaccaro et al. 2002, Ylonen et al. 2007).

The Pro12Ala genotype frequencies did not differ in subjects with and without FH of DM2 and the frequencies were comparable with other studied Caucasian cohorts (Altshuler et al. 2002). In our cohort, the analysis of the association of the Pro12Ala polymorphism with biochemical markers of insulin sensitivity, lipid profile or body composition did not reveal significant differences between the genotypes, i.e. 12Ala carriers and non-carriers, independent of FH of DM2 as in Stefanski et al. (2006). Also, basal FFA concentration was comparable across the genotypes.

The Pro12Ala genotyping across increasing quartiles of basal FFA concentration and across quartiles stratified on the basis of FFA composition showed no relationship between the frequency of the polymorphism and FFA status. Vaccaro et al.(2002) also did not show any relationship between the Pro12Ala polymorphism and fasting FFAs in the general population under physiological conditions. However, when we compared the parameters of glucose metabolism $\left(\mathrm{G}_{0}\right.$, AUC $\mathrm{G} 7$, AUC Cp7, AUC 17, Matsuda index, disposition index) in 12Pro and 12Ala carriers among the quartiles of basal FFA, 12Ala carriership was associated with the highest insulin sensitivity and disposition indices in the presence of low levels of FFAs $(<25$ th percentile). The situation was completely opposite in subjects with 12Ala allele but high FFA concentrations ( $>75$ th percentile). These people had the lowest levels of the Matsuda insulin sensitivity index, disposition indices and the highest fasting glucose and areas under the oGTT curves. Similarly, Robitaille et al. (2003) found in the Quebeck Family Study that 12Ala carriership was associated with metabolic deterioration when exposed to high fat intake. A hypothesis that indirectly fits our observations was stated by Vaccaro et al. (2007), who formulated that 12Ala carriers are more prone to weight gain when exposed to an obesogenic environment but may benefit more from energy restriction or increased energy expenditure.

The role of the 12Ala allele in the modulation of leptin levels is under debate. We observed increased leptin levels in 12Ala carriers as published in (Simon et al. 2002, Cole et al. 2000). Significance was shown in females with FH DM2. An interaction was revealed between basal FFA and Pro12Ala genotype resulting in significantly different leptin levels among FFA quartiles in Ala carriers and noncarriers. The female 12Ala carriers had nearly twice higher leptin levels in the presence of low FFA in comparison to the upper quartile.

12Ala carriership was also associated with elevated TG levels but only in the upper FFA quartile. It is partly in concordance with the hypothesis that the reduced transcriptional activity of the Ala variant might enhance the insulin-mediated inhibition of lipolysis (Stumvoll and Haring 2002b, Vaccaro et al. 2007). 
The interactions of Pro12Ala genotype with fatty acid concentration and composition with respect to $\mathrm{FH}$ of DM2 and their influence on whole body insulin sensitivity (Matsuda index) are given in Fig.1. Some trends are apparent, but significance was reached only in a few cases probably due to the relatively small number of Ala carriers in the particular quartiles. Regarding the total basal plasma FFA concentration, as expected, insulin sensitivity was higher in the lower quartile of $\mathrm{FFA}_{0}$, irrespective of Pro12Ala and FH of DM2 status. The interaction of the polymorphism with the ratio of plasmatic PUFA/SFA was evident in subjects with FH of DM2 where 12Ala carriership was associated with higher insulin sensitivity when PUFA/SFA was high. Surprisingly, the higher ratio PUFA/SFA as well as higher $\Sigma$ PUFA and \% PUFA were associated with the tendency to lower insulin sensitivity. Luan et al. (2001) described the strong interaction between dietary PUFA/SFA and Pro12Ala polymorphism for BMI and fasting insulin. The authors demonstrated that these parameters could be influenced in subjects with a given genotype in the opposite manner depending on the PUFA/SFA ratio. Moreover, this association was modified by physical activity in 12Ala carriers in multiplicative manner (Franks et al. 2004). On the contrary, Tai et al. (2004) did not find the modifying effect of PUFA/SFA on Pro12Ala in determining of BMI and fasting insulin. Soriguer et al. (2006) described higher insulin resistance in obese people with 12Ala, especially if their intake of MUFA was low. A similar, but not significant trend was seen in our groups with and without FH of DM2.

Further studies with enlarged groups and with subtypization of FFA, especially PUFA (n-6 / n-3), together with involvement of physical activity and evaluation of PPAR $\gamma 2$ expression will be necessary to prove these results.

The main outcomes of this study could be summarized: 1) Family history of DM2 was associated with lower \% PUFA, PUFA/SFA and slightly higher $\%$ MUFA. 2) Pro12Ala carriership was not associated with fasting plasma FFA concentration or composition, nor to anthropometric or metabolic markers of glucose and lipid metabolism in the tested population. 3) However, the interaction of carriership status with FFA levels influenced basal glucose levels, insulin sensitivity and disposition indices as well as triglycerides, HDLcholesterol and leptin levels, especially in women. The metabolic effects of 12Ala carriership were influenced very strongly by FFA levels - the beneficial role of 12Ala was seen only in presence of low concentration of basal plasma free fatty acids. 4) The interaction of genotype with plasma PUFA/SFA ratio significantly influenced insulin sensitivity. Surprisingly, high PUFA/SFA ratio was associated with lower insulin sensitivity and the protective effect of 12Ala allele was apparent in subjects with family history of DM2.

We are aware that our results are limited by the cross-sectional design of our study. Further, physical activity was not taken into account. Nevertherless, we suggest that our results reflect the actual genotypemetabolic interactions in fasting and oGTT stimulated conditions. On the basis of published data (Nissen and Wolski 2007) and our findings we recommend the genotyping of diabetic patients for Pro12Ala polymorphism of the PPAR $\gamma 2$ gene before treatment with thiazolidinediones and education of subjects regarding diet and physical activity which modulate metabolic outcomes.

\section{Conflict of Interest}

There is no conflict of interest.

\section{Acknowledgements}

Supported by grant IGA MH CR NR/7809-5.

\section{References}

ALTSHULER D, HIRSCHHORN JN, KLANNEMARK M, LINDGREN CM, VOHL MC, NEMESH J, LANE CR, SCHAFFNER SF, BOLK S, BREWER C, TUOMI T, GAUDET D, HUDSON TJ, DALY M, GROOP L, LANDER ES: The common PPAR $\gamma$ Pro12Ala polymorphism is associated with decreased risk of type 2 diabetes. Nat Genet 26: 76-80, 2000.

BARROSO I: Genetics of Type 2 diabetes. Diabet Med 22: 517-535, 2005.

BARROSO I, GURNELL M, CROWLEY VE, AGOSTINI M, SCHWABE JW, SOOS MA, MASLEN GL, WILLIAMS TD, LEWIS H, SCHAFER AJ, CHATTERJEE VK, O'RAHILLY S: Dominant negative mutations in human PPAR $\gamma$ associated with severe insulin resistance, diabetes mellitus and hypertension. Nature 402: 880-883, 1999. 
BLÁHA P. ANTROPO-ein Programm für automatische Beartbeitung anthropologischer Daten. Wiss. Z Humboldt-Univ Berlin 5: 153-156, 1991.

BLUHER M, PASCHKE R: Analysis of the relationship between PPAR- $\gamma 2$ gene variants and severe insulin resistance in obese patients with impaired glucose tolerance. Exp Clin Endocrinol Diabetes 111: 85-90, 2003.

CAHOVÁ M, VAVŘÍNKOVÁ H, KAZDOVÁ L: Glucose-fatty acid interaction in skeletal muscle and adipose tissue in insulin resistance. Physiol Res 56: 1-15, 2007.

CAMPBELL LV, MARMOT PE, DYER JA, BORKMAN M, STORLIEN LH: The high-monounsaturated fat diet as a practical alternative for NIDDM. Diabetes Care 17: 177-182, 1994.

COCOZZA S: Methodological aspects of the assessment of gene-nutrient interactions at the population level. Nutr Metab Cardiovasc Dis 17: 82-88, 2007.

COLE SA, MITCHELL BD, HSUEH WC, PINEDA P, BEAMER BA, SHULDINER AR, COMUZZIE AG, BLANGERO J, HIXSON JE: The Pro12Ala variant of peroxisome proliferator-activated receptor- $\gamma 2$ (PPAR$\gamma 2$ ) is associated with measures of obesity in Mexican Americans. Int J Obes Relat Metab Disord 24: 522$524,2000$.

DAS UN: A defect in the activity of delta6 and delta5 desaturases may be a factor predisposing to the development of insulin resistance syndrome. Prostaglandins Leukot Essent Fatty Acids 72: 343-350, 2005.

DEEB SS, FAJAS L, NEMOTO M, PIHLAJAMAKI J, MYKKANEN L, KUUSISTO J, LAAKSO M, FUJIMOTO W, AUWERX J: A Pro12Ala substitution in PPAR $\gamma 2$ associated with decreased receptor activity, lower body mass index and improved insulin sensitivity. Nat Genet 20: 284-287, 1998.

DUBOIS M, PATTOU F, KERR-CONTE J, GMYR V, VANDEWALLE B, DESREUMAUX P, AUWERX J, SCHOONJANS K, LEFEBVRE J: Expression of peroxisome proliferator-activated receptor $\gamma$ (PPAR $\gamma$ ) in normal human pancreatic islet cells. Diabetologia 43: 1165-1169, 2000.

FAJAS L, AUBOEUF D, RASPE E, SCHOONJANS K, LEFEBVRE AM, SALADIN R, NAJIB J, LAVILLE M, FRUCHART JC, DEEB S, VIDAL-PUIG A, FLIER J, BRIGGS MR, STAELS B, VIDAL H, AUWERX J: The organization, promoter analysis, and expression of the human PPAR $\gamma$ gene. $J$ Biol Chem 272: 18779$18789,1997$.

FESKENS EJ, LOEBER JG, KROMHOUT D: Diet and physical activity as determinants of hyperinsulinemia: the Zutphen Elderly Study. Am J Epidemiol 140: 350-360, 1994.

FORMAN BM, TONTONOZ P, CHEN J, BRUN RP, SPIEGELMAN BM, EVANS RM: 15-Deoxy- $\Delta^{12,14}$ prostaglandin $\mathrm{J}_{2}$ is a ligand for the adipocyte determination factor PPAR $\gamma$. Cell 83: 803-812, 1995.

FRANKS PW, LUAN J, BROWNE PO, HARDING AH, O'RAHILLY S, CHATTERJEE VK, WAREHAM NJ: Does peroxisome proliferator-activated receptor $\gamma$ genotype (Pro12Ala) modify the association of physical activity and dietary fat with fasting insulin level? Metabolism 53: 11-16, 2004.

GROOP L, FORSBLOM C, LEHTOVIRTA M, TUOMI T, KARANKO S, NISSEN M, EHRNSTROM BO, FORSEN B, ISOMAA B, SNICKARS B, TASKINEN MR: Metabolic consequences of a family history of NIDDM (the Botnia study): evidence for sex-specific parental effects. Diabetes 45: 1585-1593, 1996.

HUŠEK P, ŠIMEK P, TVRZICKÁ E. Simple and rapid procedure for the determination of individual free fatty acids in serum. Anal Chim Acta 465: 433-439, 2002.

JUMP DB, CLARKE SD, THELEN A, LIIMATTA M: Coordinate regulation of glycolytic and lipogenic gene expression by polyunsaturated fatty acids. J Lipid Res 35: 1076-1084, 1994.

KELLER U: From obesity to diabetes. Int J Vitam Nutr Res 76: 172-177, 2006.

KERSTEN S, DESVERGNE B, WAHLI W: Roles of PPARs in health and disease. Nature 405: 421-424, 2000.

KUNEŠOVÁ M, BRAUNEROVÁ R, HLAVATÝ P, TVRZICKÁ E, STAŇKOVÁ B, ŠKRHA J, HILGERTOVÁ J, HILL M, KOPECKÝ J, WAGENKNECHT M, HAINER V, MATOULEK M, PAŘÍZKOVÁ J, ŽÁK A, SVAČINA S: The influence of n-3 polyunsaturated fatty acids and very low calorie diet during a short-term weight reducing regimen on weight loss and serum fatty acid composition in severely obese women. Physiol Res 55: 63-72, 2006.

LAZAR MA: PPAR $\gamma, 10$ years later. Biochimie 87: 9-13, 2005. 
LEHMANN JM, MOORE LB, SMITH-OLIVER TA, WILKISON WO, WILLSON TM, KLIEWER SA: An antidiabetic thiazolidinedione is a high affinity ligand for peroxisome proliferator-activated receptor $\gamma$ (PPAR $\gamma$ ). J Biol Chem 270: 12953-12956, 1995.

LINDI V, SIVENIUS K, NISKANEN L, LAAKSO M, UUSITUPA MI: Effect of the Pro12Ala polymorphism of the PPAR- $\gamma 2$ gene on long-term weight change in Finnish non-diabetic subjects. Diabetologia 44: 925-926, 2001.

LINDI V, SCHWAB U, LOUHERANTA A, LAAKSO M, VESSBY B, HERMANSEN K, STORLIEN L, RICCARDI G, A AR: Impact of the Pro12Ala polymorphism of the PPAR- $\gamma 2$ gene on serum triacylglycerol response to n-3 fatty acid supplementation. Mol Genet Metab 79: 52-60, 2003.

LUAN J, BROWNE PO, HARDING AH, HALSALL DJ, O'RAHILLY S, CHATTERJEE VK, WAREHAM NJ: Evidence for gene-nutrient interaction at the PPAR $\gamma$ locus. Diabetes 50: 686-689, 2001.

MARSHALL JA, HOAG S, SHETTERLY S, HAMMAN RF: Dietary fat predicts conversion from impaired glucose tolerance to NIDDM. The San Luis Valley Diabetes Study. Diabetes Care 17: 50-56, 1994.

MATSUDA M, DE FRONZO RA: Insulin sensitivity indices obtained from oral glucose tolerance testing: comparison with the euglycemic insulin clamp. Diabetes Care 22: 1462-1470, 1999.

MATTHEWS DR, HOSKER JP, RUDENSKI AS, NAYLOR BA, TREACHER DF, TURNER RC: Homeostasis model assessment: insulin resistance and beta-cell function from fasting plasma glucose and insulin concentrations in man. Diabetologia 28: 412-419, 1985.

MC GARRY JD: Banting lecture 2001: dysregulation of fatty acid metabolism in the etiology of type 2 diabetes. Diabetes 51: 7-18, 2002.

MEMISOGLU A, HU FB, HANKINSON SE, MANSON JE, DE VIVO I, WILLETT WC, HUNTER DJ: Interaction between a peroxisome proliferator-activated receptor $\gamma$ gene polymorphism and dietary fat intake in relation to body mass. Hum Mol Genet 12: 2923-2929, 2003.

NISKANEN L, LINDI V, ERKKILA A, SIVENIUS K, LUOMA J, YLA-HERTTUALA S, LAAKSO M, UUSITUPA MI: Association of the Pro12Ala polymorphism of the PPAR- $\gamma 2$ gene with oxidized low-density lipoprotein and cardiolipin autoantibodies in nondiabetic and type 2 diabetic subjects. Metabolism 52: 213-217, 2003.

NISSEN SE, WOLSKI K: Effect of rosiglitazone on the risk of myocardial infarction and death from cardiovascular causes. $N$ Engl J Med 356: 2457-2471, 2007.

PARILLO M, RIVELLESE AA, CIARDULlO AV, CAPALDO B, GIACCO A, GENOVESE S, RICCARDI G: A high-monounsaturated-fat/low-carbohydrate diet improves peripheral insulin sensitivity in non-insulindependent diabetic patients. Metabolism 41: 1373-1378, 1992.

PARKER DR, WEISS ST, TROISI R, CASSANO PA, VOKONAS PS, LANDSBERG L: Relationship of dietary saturated fatty acids and body habitus to serum insulin concentrations: the Normative Aging Study. Am $J$ Clin Nutr 58: 129-136, 1993.

PISABARRO RE, SANGUINETTI C, STOLL M, PRENDEZ D: High incidence of type 2 diabetes in peroxisome proliferator-activated receptor $\gamma 2$ Pro12Ala carriers exposed to a high chronic intake of trans fatty acids and saturated fatty acids. Diabetes Care 27: 2251-2252, 2004.

ROBITAILLE J, DESPRES JP, PERUSSE L, VOHL MC: The PPAR- $\gamma$ P12A polymorphism modulates the relationship between dietary fat intake and components of the metabolic syndrome: results from the Quebec Family Study. Clin Genet 63: 109-116, 2003.

SCHOONJANS K, WATANABE M, SUZUKI H, MAHFOUDI A, KREY G, WAHLI W, GRIMALDI P, STAELS B, YAMAMOTO T, AUWERX J: Induction of the acyl-coenzyme A synthetase gene by fibrates and fatty acids is mediated by a peroxisome proliferator response element in the C promoter. J Biol Chem 270: 1926919276, 1995.

SIMON I, VENDRELL J, GUTIERREZ C, FERNANDEZ-REAL JM, VENDRELL I, GALLART L, FONTOVA R, RICHART C: Pro12Ala substitution in the peroxisome proliferator-activated receptor- $\gamma$ is associated with increased leptin levels in women with type-2 diabetes mellitus. Horm Res 58: 143-149, 2002. 
SORIGUER F, MORCILLO S, CARDONA F, ROJO-MARTINEZ G, DE LA CRUZ ALMARAZ M, RUIZ DE ADANA MDE L, OLVEIRA G, TINAHONES F, ESTEVA I: Pro12Ala polymorphism of the PPAR $\gamma 2$ gene is associated with type 2 diabetes mellitus and peripheral insulin sensitivity in a population with a high intake of oleic acid. J Nutr 136: 2325-2330, 2006.

STEFAN N, FRITSCHE A, HARING H, STUMVOLL M: Effect of experimental elevation of free fatty acids on insulin secretion and insulin sensitivity in healthy carriers of the Pro12Ala polymorphism of the peroxisome proliferator--activated receptor- $\gamma 2$ gene. Diabetes 50: 1143-1148, 2001.

STEFANSKI A, MAJKOWSKA L, CIECHANOWICZ A, FRANKOW M, SAFRANOW K, PARCZEWSKI M, PILARSKA K: Lack of association between the Pro12Ala polymorphism in PPAR- $\gamma 2$ gene and body weight changes, insulin resistance and chronic diabetic complications in obese patients with type 2 diabetes. Arch Med Res 37: 736-743, 2006.

STORLIEN LH, JENKINS AB, CHISHOLM DJ, PASCOE WS, KHOURI S, KRAEGEN EW: Influence of dietary fat composition on development of insulin resistance in rats. Relationship to muscle triglyceride and omega-3 fatty acids in muscle phospholipid. Diabetes 40: 280-289, 1991.

STUMVOLL M, HARING H: The peroxisome proliferator-activated receptor- $\gamma 2$ Pro12Ala polymorphism. Diabetes 51: 2341-2347, 2002a.

STUMVOLL M, HARING H: Reduced lipolysis as possible cause for greater weight gain in subjects with the Pro12Ala polymorphism in PPAR $\gamma 2$ ? Diabetologia 45: 152-153, 2002b.

TAI ES, CORELLA D, DEURENBERG-YAP M, ADICONIS X, CHEW SK, TAN CE, ORDOVAS JM: Differential effects of the C1431T and Pro12Ala PPAR $\gamma$ gene variants on plasma lipids and diabetes risk in an Asian population. J Lipid Res 45: 674-685, 2004.

TAKADA R, SAITOH M, MORI T: Dietary $\gamma$-linolenic acid-enriched oil reduces body fat content and induces liver enzyme activities relating to fatty acid beta-oxidation in rats. J Nutr 124: 469-474, 1994.

TAN GD, NEVILLE MJ, LIVERANI E, HUMPHREYS SM, CURRIE JM, DENNIS L, FIELDING BA, KARPE F: The in vivo effects of the Pro12Ala PPAR $\gamma 2$ polymorphism on adipose tissue NEFA metabolism: the first use of the Oxford Biobank. Diabetologia 49: 158-168, 2006.

UUSITUPA M: Gene-diet interaction in relation to the prevention of obesity and type 2 diabetes: evidence from the Finnish Diabetes Prevention Study. Nutr Metab Cardiovasc Dis 15: 225-233, 2005.

VACCARO O, LAPICE E, MONTICELLI A, GIACCHETTI M, CASTALDO I, GALASSO R, PINELLI M, DONNARUMMA G, RIVELLESE AA, COCOZZA S, RICCARDI G: Pro12Ala polymorphism of the PPAR $\gamma 2$ locus modulates the relationship between energy intake and body weight in type 2 diabetic patients. Diabetes Care 30: 1156-1161, 2007.

VACCARO O, MANCINI FP, RUFFA G, SABATINO L, IOVINE C, MASULLI M, COLANTUONI V, RICCARDI G: Fasting plasma free fatty acid concentrations and Pro12Ala polymorphism of the peroxisome proliferatoractivated receptor (PPAR) $\gamma 2$ gene in healthy individuals. Clin Endocrinol (Oxf) 57: 481-486, 2002.

VESSBY B, GUSTAFSSON IB, TENGBLAD S, BOBERG M, ANDERSSON A: Desaturation and elongation of fatty acids and insulin action. Ann N Y Acad Sci 967: 183-195, 2002.

VIDAL-PUIG AJ, CONSIDINE RV, JIMENEZ-LINAN M, WERMAN A, PORIES WJ, CARO JF, FLIER JS: Peroxisome proliferator-activated receptor gene expression in human tissues. Effects of obesity, weight loss, and regulation by insulin and glucocorticoids. J Clin Invest 99: 2416-2422, 1997.

YEN CJ, BEAMER BA, NEGRI C, SILVER K, BROWN KA, YARNALL DP, BURNS DK, ROTH J, SHULDINER AR: Molecular scanning of the human peroxisome proliferator activated receptor $\gamma$ (hPPAR $\gamma$ ) gene in diabetic Caucasians: identification of a Pro12Ala PPAR- $\gamma 2$ missense mutation. Biochem Biophys Res Commun 241: 270-274, 1997.

YLONEN SK, SALMINEN I, LYSSENKO V, VIRTANEN SM, GROOP L, ARO A, SALORANTA C: The Pro12Ala polymorphism of the PPAR- $\gamma 2$ gene affects associations of fish intake and marine n-3 fatty acids with glucose metabolism. Eur J Clin Nutr, 2007 [In press]

YOUNG RP, CRITCHLEY JA, ANDERSON PJ, LAU MS, LEE KK, CHAN JC: The short insulin tolerance test: feasibility study using venous sampling. Diabet Med 13: 429-433, 1996. 
ŽÁK A, TVRZICKÁ E, ZEMAN M, VECKA M: Pathophysiology of and clinical significance of polyunsaturated fatty acids n-3 family. [In Czech] Cas Lek Cesk 144 (Suppl) 1: 6-18, 2005. 